\title{
Rare Book Cataloging
}

How to Catalog a Rare Book. By Paul Shaner Dunkin. Chicago, American Library Association, 1951. vii, 85p. \$1.75.

It will be a surprise to many a reader to learn that a cataloger from the Folger Shakespeare Library has succeeded in describing in simple, layman's English the intricacies that are the foundations of rare book cataloging. In a mere 85 pages he has lifted the iron curtain behind which most catalogers of ordinary books (as he calls them) have been too timid to look.

There is a serious danger, however, that catalogers and library administrators may be misled by this simplicity and assume that the task is as simple as this explanation of it. The critical reader will soon discover that in spite of the opening chapter entitled "Whys and Wherefores," there are many questions left unanswered. In his first paragraph, $\mathrm{Mr}$. Dunkin says that "catalogers dream of a brave new world in which simplified cataloging will answer all needs of all books." $\mathrm{He}$ then promptly explains that what he has suggested in the following pages for rare book description is really simplified cataloging and he falls into his own trap. His dreams of simplified descriptions for rare books should answer the needs of all rare books. His basic fallacy as I see it is his failure to attempt to define a rare book which he says is not the cataloger's job. Even if one ac- cepts his premise that "any book which has value as a physical object is a rare book," it is possible to concede this in a day of good photoduplication services one must admit that different physical qualities may have caused the rarity, and correspondingly different descriptions may be required to catalog such books adequately without giving unnecessary information. To suggest that if the convention of quasi-facsimile transcription of title pages is not adopted, the transcription must give line endings in every case ("The general cataloger ... will do well to mark line endings in all transcriptions because it is so little trouble that omitting them results in no saving") is to provide guidance to be followed without the discriminating mind that it is necessary for a cataloger of rare books to have.

Intelligent cataloging requires that the cataloger see the relationships between books. The cataloger of rare books in many cases must make finer distinctions in the relationships and be able to express clearly and concisely what he has discovered. This brief treatise may be a godsend to guide the beginner in the presentation of his bibliographical data, but it needs to be supplemented by a guide that leads the cataloger to the sources of information that tell him why his particular book is rare-Lucile M. Morsch, $\mathrm{Li}$ brary of Congress.

\section{ILO Publications}

Catalogue of Publications in English of the International Labour Office, 1919-1950. Geneva, The Library, International Labour Office, 1951. 379p. (Mimeographed.) Limited free distribution.

This volume, issued as Bibliographical Contributions No.5, is the first attempt at a complete listing of the English language publications of the International Labour Office. Two years ago a corresponding catalog was issued for French language publications (Bibliographical Contributions No.I) and a supplement for 1949 publications followed. Since the French catalog is out of print, the librarian, Joseph Wilson Haden, has announced that the library is preparing a new edition covering the period 1919-1950, which they hope to bring out later this year as No. 6 of the series.

The Catalogue of Publications in English is arranged in two parts: The first part is a dictionary catalog with full bibliographic information for each entry; the second part is a checklist arranged by conference, committee or other body, and by series. The latter should be exceedingly useful for libraries in checking their holdings and in identifying the somewhat complex publications of international labour conferences. For prices of ILO documents reference must be made to the Abridged Catalogue of Publications which is frequently revised. 